\title{
Epidemiology of Mycoplasma bovis in Pennsylvania veal calves
}

\author{
M. K. Soehnlen, ${ }^{\star}$ A. Aydin,† K. S. Murthy,‡ E. J. Lengerich,§ A. L. Hattel, ${ }^{\star}$ B. A. Houser, ${ }^{\star}$ G. D. Fenton, ${ }^{\star}$ \\ H. R. Lysczek, ${ }^{\star}$ C. M. Burns, ${ }^{\star}$ A. M. Townsend, ${ }^{\star}$ J. W. Brooks, ${ }^{\star}$ D. R. Wolfgang, ${ }^{\star}$ and B. M. Jayarao ${ }^{\star 1}$ \\ *Department of Veterinary and Biomedical Sciences, The Pennsylvania State University, University Park 16802 \\ †Marcho Farms Inc., Harleysville, PA 19438 \\ łUniversity of Phoenix, Chicago Campus, Schaumburg, IL 60173 \\ §Department of Public Health Sciences, The Pennsylvania State University Medical School, Hershey 17033
}

\begin{abstract}
The objective of the study was to estimate the prevalence and incidence of Mycoplasma bovis, a common cause of pneumonia, in veal calves. Using simple random sampling, 252 calves from 4 veal herds located in central Pennsylvania were selected and longitudinally followed for monthly collection of nasal swabs. Bronchial swabs and lung lesions were collected at the slaughterhouse. Nasal, bronchial, and lung lesion swabs were cultured for bacterial respiratory pathogens. Ninety lung lesions were identified, of which 41.1, 1.1, 1.1, 7.8, and $4.4 \%$ were culture positive for $M$. bovis alone, Pasteurella multocida alone, Mannheimia haemolytica alone, M. bovis and P. multocida co-infection, and M. bovis and $M$. haemolytica co-infection, respectively. The data indicate that potential interventions, such as therapeutics, vaccines, or management control measures, would be most effective before $50 \mathrm{~d}$ of age based upon the cumulative incidence of colonization.
\end{abstract}

Key words: cattle, epidemiology, Mycoplasma bovis

\section{INTRODUCTION}

Mycoplasma bovis, an important etiologic agent of calf pneumonia, is also commonly associated with arthritis, mastitis, conjunctivitis, and otitis (Nicholas and Ayling, 2003). An estimated one-quarter to one-third of pneumonia-related illnesses in growing cattle may be attributed to M. bovis infections (Nicholas et al., 2000). Additionally, cattle infected with $M$. bovis may serve as a reservoir of infection by shedding the bacteria from the respiratory tract for many months following initial colonization (Pfutzner, 1990). Calves less than 4 mo of age are at a highest risk of respiratory disease due to M. bovis (Stipkovits et al., 2000; Nicholas and Ayling, 2003). Mycoplasma bovis may act as a predisposing factor that weakens the host immune system, leading to

Received February 25, 2011.

Accepted September 10, 2011.

${ }^{1}$ Corresponding author: bmj3@psu.edu invasion by other pathogenic bacteria or viruses, which may explain the chronic and polymicrobial nature of $M$. bovis infections (Rosengarten and Citti, 1999; Snowder et al., 2006). The severity of calf pneumonia is further compounded by animal husbandry, the environment, low efficacy of many antimicrobials, and unknown efficacy of vaccines (Nicholas et al., 2000, 2009).

Little is known about the age of onset and duration of nasal shedding of $M$. bovis in young calves. It has been suggested that $M$. bovis prevalence peaks between 1 and 4 mo of age, but it is not known at which point in those months is highest regardless of differences between geography (Bennett and Jasper, 1977). Special-fed veal calves are reared in temperature-controlled housing in which they can interact with neighboring calves, potentially leading to the transmission of $M$. bovis. Calves may become infected with $M$. bovis within the first days of life through ingestion of infected colostrum from the dam (Pfutzner and Sachse, 1996). Airborne exposure is likely a major route of transmission in barns (Jasper et al., 1974).

Estimates of the prevalence of $M$. bovis infection on farms are wide ranging, with reports around the world between 26 and 100\% (Langford, 1977; Pignatelli, 1978; Muenster et al., 1979; Adegboye et al., 1995; Poumarat et al., 2001; Arcangioli et al., 2008; Gerchman et al., 2009). One pair of reports from Ontario, Canada, noted that $M$. bovis was isolated from $98 \%$ of cattle with chronic pneumonia (Gagea et al., 2006b). Another report from Ontario indicated that $46 \%$ of healthy calves had M. bovis infection (Gagea et al., 2006a). Because few reports exist of $M$. bovis-associated pneumonia in young calves, it is difficult to estimate the effect of the individual components of multifactorial diseases, such as pneumonia. Currently, no reports are found regarding the incidence, prevalence, or attack rates of veal calf pneumonia associated with $M$. bovis in the United States.

The similarities of age, sex, barn temperature, and diet of special-fed veal calf populations from this study are especially advantageous in researching infectious diseases that affect young calves. The objectives of this 
study were to (1) determine the incidence, prevalence, and attack rates of $M$. bovis in Pennsylvania specialfed veal calves; (2) examine whether $M$. bovis found through nasal swab screening is associated with disease of the lower respiratory tract; and (3) assess the effect of the veal housing air environment upon disease through environmental air sampling.

\section{MATERIALS AND METHODS}

All animal research was approved and conducted in accordance with Pennsylvania State University Office of Research Protections.

\section{Study Populations and Sample Collection}

The largest veal production company in the United States was recruited for participation in this study. According to company policy, healthy, unaltered 3- to 7-d-old male dairy calves with an average weight of 48 $\mathrm{kg}(\sim 105 \mathrm{lbs})$ were purchased from livestock auctions in Pennsylvania and lower New York and transported to 1 of 4 cooperating veal growers. Calves were cared for according to the standard operating procedures of the veal production company. Individual sick calves were treated according to normal farm protocols under the supervision of their veterinary practitioner. The diet for each calf consisted of an all-milk milk replacer containing iron and approximately 40 other essential nutrients. Routine veterinary care, including vaccination against bovine viral diarrhea virus (BVDV; types 1 and 2), bovine herpes virus (BHV-1), bovine respiratory syncytial virus (BRSV), and parainfluenzae type 3 virus $\left(\mathbf{P I}_{3}\right)$, was administered to each animal.

Calves in 3 (herds B, C, D) of the 4 herds were housed in separate stalls. Calves in herd A were housed 2 per stall; dividers in each stall separated the calves until approximately $8 \mathrm{wk}$ of age when dividers were removed. The 4 selected herds had 3 different managers (herds $\mathrm{A}$ and $\mathrm{D}$ had different managers and workers, whereas herds $\mathrm{B}$ and $\mathrm{C}$ shared the same manager and workers). The distance between herds ranged between 16 and 64 $\mathrm{km}$. Herds B and C were raised between October 27, 2008, and March 13, 2009, and between March 27 and August 10, 2009, respectively. Herd A was raised from September 8, 2008, to January 19, 2009. Herd D was raised from March 4 to July 21, 2009. When the calves reached a sale weight of $205 \mathrm{~kg}(\sim 145 \mathrm{~d}$ of age), they were shipped to a common facility for slaughter and processing.

Calves were randomly assigned to a stall upon entry into each barn. In total, 252 calves from 4 herds (identified by unique ear tag) were selected using simple random sampling within each stratified unit and subsequently sampled for bacterial respiratory pathogens. A sterile, rayon-tipped swab with polyurethane plastic shaft (BBL Aimes media CultureSwab, Becton-Dickinson, Franklin Lakes, NJ) was inserted in the nostril to a depth of $\sim 10 \mathrm{~cm}$. Sampling of calves began $3 \mathrm{~d}$ after arrival in the barn and at 30- to 40-d intervals thereafter, ending with a final swab collection $7 \mathrm{~d}$ before slaughter, for a total of 4 or 5 samplings. Herds A and $\mathrm{B}$ were sampled 4 times, whereas herds C and D were sampled 5 times due to timing of sampling visits. Samplings 4 and 5 (herds C and D) were combined into one data point (81-149 d), with a positive result assigned to positive swabs collected from either collection time to align with the other 2 herd ages for analysis. Swabs were transported on ice and cultured within $7 \mathrm{~h}$ of collection.

At slaughter, an incision was made in the trachea and a swab was used to sample the bronchial bifurcation. Lung lesions were identified by visual inspection for gross lesions characteristic for pleural pneumonia, pleuritis, or gross pathology consistent with pneumonia and excised by a veterinarian (DRW, JWB, or BMJ). All bronchial swabs and lung lesions were transported on ice and cultured within $24 \mathrm{~h}$ of collection. A representative sample of sections of tissue $(n=9)$ were fixed in $10 \%$ buffered formalin, embedded in paraffin, sectioned, and stained with hematoxylin-eosin stain at the Pennsylvania State University Animal Diagnostic Laboratory (University Park). Histopathology was performed by a veterinary pathologist (ALH).

\section{Environmental Air Sampling}

Environmental air samples were collected using the all glass impinger bio-aerosol system, Vac-U-Go (SKC Inc., Eighty-Four, PA) with a $12.5 \mathrm{~L} / \mathrm{min}$ air intake. The sampler was run from a height of $0.4 \mathrm{~m}$ for 30 min in the center of the barn. Sampling was performed before entry of calves and at approximately 1-mo intervals after calves arrived, resulting in 22 sample collections. The sampling medium placed in the collection vial of the impinger was a pleuropneumonia-like organism (PPLO) broth with Mycoplasma enrichment without inhibitors (Becton Dickinson, Sparks, MD). No antifoam A was added because no issues of foaming occurred during sampling during the preliminary testing. Preliminary testing with an aerosolized $M$. bovis sample (ATCC 25523) under a closed laminar hood indicated the ability of the media and unit to adequately collect sample. The sample was stored on ice in a cooler for transportation to the laboratory. Samples were cultured within $7 \mathrm{~h}$ of collection. 


\section{Culturing}

In the laboratory, the surface of the lung lesion tissue was seared. An incision was then made with a sterile scalpel, and a sterile cotton tipped swab (Puritan Medical Products, Guilford, ME) was inserted into the core of the tissue sample. Nasal swabs, bronchial bifurcation swabs, and lung lesion swabs were cultured on blood agar (BA) or MacConkey (MAC) agar at $37^{\circ} \mathrm{C}$ in an aerophilic environment, and on chocolate agar $(\mathbf{C A}$; all agars from Becton Dickinson) at $37^{\circ} \mathrm{C}$ in a microaerophilic environment. Standard biochemical identification procedures and the API system (BioMerieux, France) were used for identification of common bovine respiratory pathogens. All swabs were then enriched in Mycoplasma enrichment broth supplemented with penicillin (UC Davis Biological Media Services, Davis, CA) for 48 $\mathrm{h}$ before being plated on PPLO agar plates (UC Davis Biological Media Services). All mycoplasma cultures were grown at $37^{\circ} \mathrm{C}$ in a microaerophilic environment. The PPLO agar plates were considered negative if no growth was noted by d 10 .

Confirmation of mycoplasma growth was performed using PCR of the uvrC $M$. bovis housekeeping gene as described by Thomas et al. (2004) and general mycoplasma primers for other Mycoplasma sp. (Nicholas et al., 2008). The DNA was extracted from 3-mL aliquots of stationary-phase cultures using the phenol-chloroform procedure described previously (Pospiech and Neumann, 1995). Briefly, culture pellet was suspended in a Tris-EDTA solution ( $\mathrm{pH}$ 7.5) with lysozyme and treated with proteinase $\mathrm{K}$ before addition of phenolchloroform. The aqueous phase was washed multiple times using ethanol and resuspended in sterile water. The American Type Culture Collection (ATCC) M. bovis standard strain PG45, accession number 25523, was used as a positive control.

Aliquots of environmental air sample inoculum (100 $\mu \mathrm{L}$ each) were spread-plated on BA, MAC, CA, Sabouraud dextrose agar (Becton Dickinson), and PPLO agars. The BA and MAC plates were incubated at $37^{\circ} \mathrm{C}$ under aerophilic conditions. One plate of Sabouraud dextrose agar was incubated at $32^{\circ} \mathrm{C}$ and another at $37^{\circ} \mathrm{C}$ under aerophilic conditions. The CA and PPLO plates were incubated at $37^{\circ} \mathrm{C}$ in a microaerophilic environment. Standard biochemical identification procedures and the API system (BioMerieux) were used for identification of bacteria.

\section{Statistical Methods}

Risk factors for the categorical outcome variables (i.e., presence or absence of respiratory pathogens) were compared using chi-squared tests, whereas risk factors for quantitative outcome variables (i.e., weights) were compared using independent sample $t$-tests using GraphPad Prism version Five (GraphPad Software Inc., La Jolla, CA). The 95\% CI were calculated using the modified Wald method. For the cumulative incidence, the goodness of fit for the curve linearity was determined using R-squared analysis (Excel 2007, Microsoft Corp., Redmond, WA). The odds ratio (OR) was calculated using $2 \times 2$ contingency tables using EpiInfo2002 v 3.5.1 (EpiInfo, Atlanta, GA). The Pvalue of OR analysis was determined using the Fisher exact test. Using SAS software (SAS Institute Inc., Cary, NC), one-way ANOVA (with Tukey HSD test) and correlation matrix were used for effects on weight gain, whereas linear sequential sampling testing and ztest (independent groups) were performed to determine the cumulative incidence of bacterial pathogen presence based upon days on feed (age) using the Pearson coefficient. Repeated measures of nasal swab samplings were assessed using 2-way repeated measure ANOVA (SAS Institute Inc.). The procedures and assumptions used in SAS included adequate repeated random sampling, exponential smoothing, and a 95\% CI for all hypotheses testing based upon statistical method and probability technique model. For 2 -sided tests, a $P$-value of $<0.05$ was considered significant.

\section{RESULTS}

\section{Upper Respiratory Tract Colonization and Lung Infection}

Samples were collected from 252 calves (3 additional calves died before completion of sampling and were considered lost to follow-up and not included in any statistical analysis), which represented $25 \%$ of the total population of the 4 herds. The period prevalence of M. bovis colonization across all observation points and herds sampled was $90.5 \%$ (95\% CI: $86.2-93.6 \%$ ) for the nasal swabs and $40.0 \%$ (95\% CI: $32.3-44.2 \%$ ) for the bronchial swabs. The highest point prevalence of $M$. bovis colonization from nasal swabs in herds A, B, C, and $\mathrm{D}$ was $76.0,64.0,90.4$, and $70.0 \%$ acquired after $\mathrm{d}$ 50 for each herd, respectively. For bronchial swabs, the prevalence at slaughter was $71.0,40.0,23.1$, and $31.1 \%$, respectively. The overall percentage of calves with at least one positive nasal swab were 77.8, 90.0, 92.3, and $93.0 \%$ for herds, A, B, C, and D, respectively (Table 1 ). The attack rate, defined as the cumulative incidence of M. bovis upper respiratory tract (URT) colonization for each specified period was shown to be highest after $50 \mathrm{~d}$ of age for all the herds sampled (Table 1). Herds A, B, and D had the highest attack rates between 81 and 140 $\mathrm{d}$ of age, whereas herd $\mathrm{C}$ had the highest between 51 


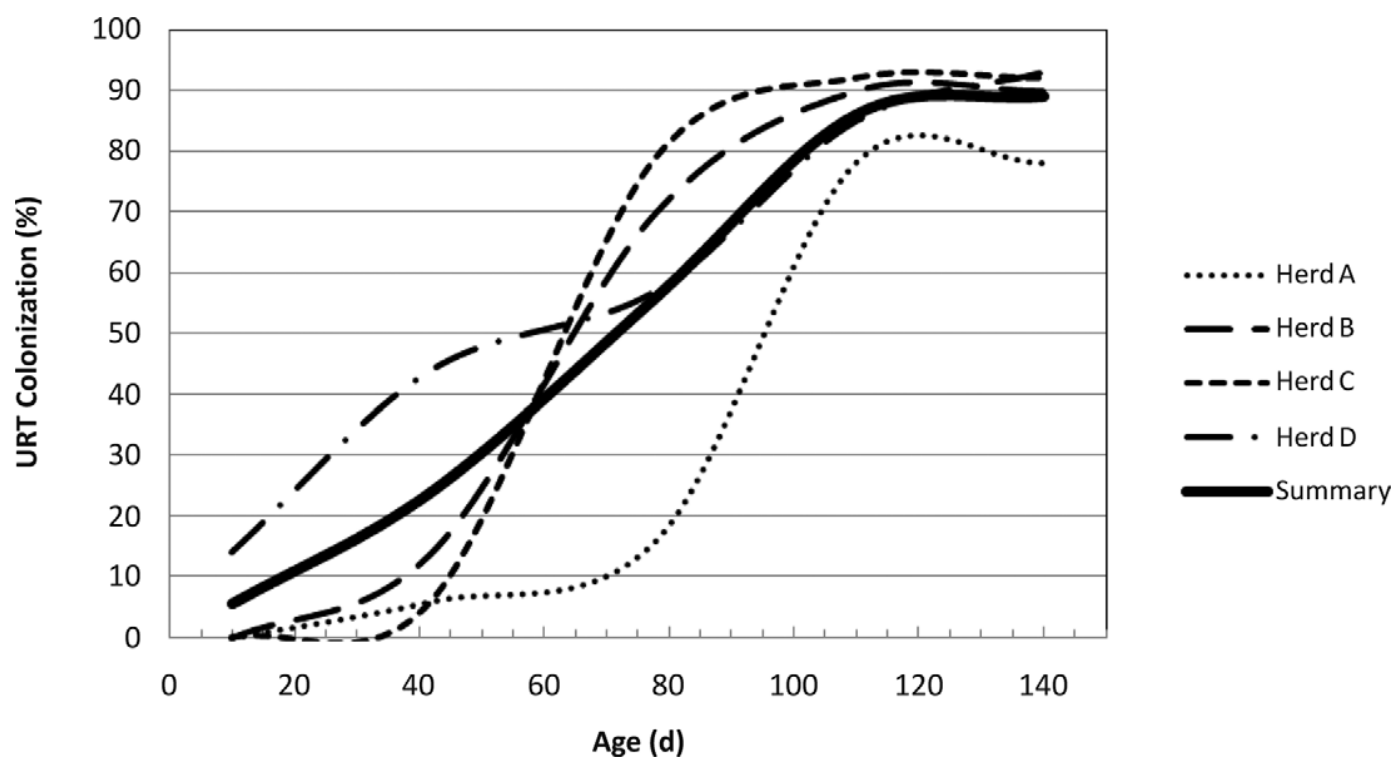

Figure 1. Mycoplasma bovis colonization trends in veal calves from Pennsylvania. Cumulative incidence trends of $M$. bovis upper respiratory tract (URT) by nasal swab for herd A $(\mathrm{n}=50)$, herd B $(\mathrm{n}=50)$, herd C $(\mathrm{n}=52)$, herd $\mathrm{D}(\mathrm{n}=100)$, and summary of all veal calves studied $\left(\mathrm{R}^{2}\right.$ of summary line $\left.=0.9655\right)$.

and $80 \mathrm{~d}$ of age. The cumulative incidence rate for each herd is similar to the attack rate; however, herds B and $\mathrm{C}$ indicate approximately level attack rates between 51 and $140 \mathrm{~d}$ of age, whereas the cumulative incidence continued to increase. The cumulative incidence of $M$. bovis URT colonization $\left(\mathrm{R}^{2}=0.97\right)$ indicated a strong relationship between age and $M$. bovis colonization in the URT for each herd, as shown in Figure 1.

Ten calves from herd D could not be identified by ear tag at the slaughterhouse and were considered lost to follow-up for all calculations involving bronchial swabs and lung lesions. Ninety (37.2\%; 95\% CI: 31-43\%) lung lesions were identified from the 242 individual calves sampled at slaughter for the 4 herds, of which $41.1 \%$ contained M. bovis (Table 2). Herds A, B, C, and D rep- resented $27,4,37$, and 22 of the total lung lesions collected, respectively. Mycoplasma bovis was successfully cultured from 15, 3, 7, and 12 lung lesions collected from herds A, B, C, and D, respectively. A significant difference in both the number of calves found to have lung lesions and lung lesions with $M$. bovis was found between herds B and C $(P<0.05)$. Ninety-four percent of calves that were culture positive at slaughter also had at least one culture-positive nasal swab during the study. Although lung lesions were 2 times more likely to be observed in calves that had at least one $M$. bovis positive nasal swab (OR $=1.99 ; 95 \%$ CI: 0.45-8.87), the findings were not significant. A single $M$. bovis positive nasal swab was not shown to be positively linked to odds of finding a positive bronchial swab $(\mathrm{OR}=$

Table 1. Summary of Mycoplasma bovis incidence rates, attack rates, and mortality for calves in study

\begin{tabular}{|c|c|c|c|c|c|}
\hline Item & $\begin{array}{c}\text { Herd A } \\
(\mathrm{n}=50)\end{array}$ & $\begin{array}{l}\text { Herd B } \\
(\mathrm{n}=50)\end{array}$ & $\begin{array}{c}\text { Herd C } \\
(\mathrm{n}=52)\end{array}$ & $\begin{array}{l}\text { Herd D } \\
(\mathrm{n}=100)\end{array}$ & $\begin{array}{l}\text { Combined } \\
(\mathrm{n}=252)\end{array}$ \\
\hline $\begin{array}{l}\text { Percentage of calves with at least one positive } \\
M \text {. bovis sample from the URT }{ }^{1} \text { by } 140 \mathrm{~d} \text { of age }\end{array}$ & 77.8 & 90.0 & 92.3 & 93.0 & 90.5 \\
\hline$(95 \% \mathrm{CI})^{2}$ & $(64.6-87.4)$ & $(78.2-96.1)$ & $(81.3-97.5)$ & $(86.0-96.8)$ & $(86.2-93.6)$ \\
\hline$P$-value ${ }^{3}$ & $<0.001$ & $<0.001$ & $<0.001$ & $<0.001$ & $<0.001$ \\
\hline \multicolumn{6}{|l|}{$\begin{array}{l}\text { Attack rates (\%) for } M \text {. bovis URT } \\
\text { colonization (95\% CI) at age: }\end{array}$} \\
\hline $0-15 \mathrm{~d}$ & $0.0(0.0-0.09)$ & $0.0(0.00-0.09)$ & $0.0(0.0-0.06)$ & $14.0(0.08-0.23)$ & $5.6(3.3-9.2)$ \\
\hline $16-50 \mathrm{~d}$ & $6.0(1.4-16.8)$ & $16.0(8.1-28.8)$ & $17.0(9.2-30.0)$ & $34.8(25.6-45.4)$ & $21.0(16.3-26.6)$ \\
\hline $51-80 \mathrm{~d}$ & $10.6(4.2-23.0)$ & $66.7(51.5-79.1)$ & $76.7(62.1-87.0)$ & $23.2(14.0-36.0)$ & $42.0(35.2-49.2)$ \\
\hline $81-140 \mathrm{~d}$ & $76.2(61.3-86.7)$ & $71.4(45.0-88.7)$ & $60.6(43.7-73.4)$ & $85.7(74.0-92.8)$ & $78.0(69.3-84.8)$ \\
\hline
\end{tabular}

\footnotetext{
${ }^{1} \mathrm{URT}=$ upper respiratory tract.

${ }^{2} 95 \%$ CI by the modified Wald method.

${ }^{3} P$-value determined by z-test.
} 
Table 2. The percentage of observed bacterial respiratory disease agents in lung lesion and bronchial bifurcation swabs collected at the slaughterhouse for 4 herds of special-fed veal calves

\begin{tabular}{lcc}
\hline & \multicolumn{2}{c}{ Percentage $\left(95 \% \mathrm{CI}^{1}\right)$} \\
\cline { 2 - 3 } Agent & $\begin{array}{c}\text { Lung lesion } \\
(\mathrm{n}=90)\end{array}$ & $\begin{array}{c}\text { Bronchial bifurcation }+ \\
(\mathrm{n}=102)\end{array}$ \\
\hline Mycoplasma bovis only & 28.9 & 36.8 \\
& $(20.5-39.0)$ & $(30.9-43.0)$ \\
Pasteurellaceae ${ }^{2}$ only & 2.2 & 1.7 \\
Co-infection of $M$. bovis and Pasteurellaceae & $(0.13-8.2)$ & $(0.5-4.3)$ \\
No bacterial respiratory pathogen growth & 12.2 & $(1.6-6.5)$ \\
& $(6.8-20.7)$ & 58.2 \\
& 56.7 & $(52.0-64.3)$ \\
\hline
\end{tabular}

${ }^{1} 95 \%$ CI by the modified Wald method.

${ }^{2}$ Pasteurellaceae include Mannheimia haemolytica and Pasteurella multocida in this study.

0.17; 95\% CI: $0.06-0.45)$. The total number of positive nasal swabs collected over the $145 \mathrm{~d}$ in the barn was not found to be linked to the presence of lung lesions containing $M$. bovis. Histopathology of a representative sample of collected tissues $(\mathrm{n}=9)$ indicated minimal, mild, or moderate multifocal interstitial pneumonia. One calf from herd $\mathrm{C}$ was determined to have $M y$ coplasma dispar present in the lung culture. Because of the low number of non-bovis species identified, the sample was excluded from statistical analysis.

Co-infections of $M$. bovis and either Pasteurella multocida or Mannheimia haemolytica were present in 11 $(12.2 \%)$ of the 90 lung lesions (Table 2). In total, 1 (3.7\%), 3 (75\%), 3 (8.1\%), and 4 (18.2\%) lung lesions were associated with more than one respiratory pathogen for herds A, B, C, and D, respectively. Pasteurella multocida was found concurrently with $M$. bovis most often $(\mathrm{n}=7)$. Mannheimia haemolytica was also found concurrently with $M$. bovis $(\mathrm{n}=4)$. Calves infected with a member of the Pasteurellaceae family (M. haemolytica and P. multocida) found in lung lesions were 10.8 (OR $=10.79 ; 95 \%$ CI: 2.23-52.32) times more likely to also have $M$. bovis present in the lesion than Pasteurellaceae alone. Forty-two percent of bronchial swabs had at least one respiratory bacterial pathogen cultured. The most frequently cultured respiratory pathogen from lung lesions (41.1\%) and bronchial swabs $(40.1 \%)$ was $M$. bovis (Table 2). Calves with a member of the Pasteurellaceae family found in the bronchial swab were 3.2 times more likely to also have $M$. bovis present, which was not significant in this study $(\mathrm{OR}=3.16 ; 95 \% \mathrm{CI}$ : 0.93-10.83).

\section{Effects of M. bovis on Weight Gain}

Individual calf weights at time of entry into the barn and the dress weights of the calves at the slaughterhouse were normally distributed for each individual herd and across herds. The average dress weight (carcass weight) for calves from herds A, B, C, and D was $112.45 \pm$ $16.90,126.05 \pm 13.21,126.05 \pm 11.02$, and $125.30 \pm$ $13.19 \mathrm{~kg}$, respectively. A significant difference $(P=$ 0.0001 ) was found between the dress weight of calves from herd A and that in the other herds. Difference in the dress weight for calves with $M$. bovis culturepositive lung lesions compared with calves without lung lesions was not significant for any herd. The difference in dress weight for calves with Pasteurellaceae culturepositive lung lesions compared with calves without lung lesions was not significant. The overall mortality rate for calves in the $140 \mathrm{~d}$ study was 11.88 per 1,000 calves.

\section{Environmental Air Sampling}

Neither Mycoplasma nor Pasteurella species were isolated from the air samples $(\mathrm{n}=22)$. The genera of bacteria that were identified from the air samples included Staphylococcus, Aerococcus, Micrococcus, Kocuria, Enterococcus, Lactococcus, Pseudomonas, and Bacillus (Table 3).

\section{DISCUSSION}

Bovine respiratory disease (BRD), an infectious bronchopneumonia, is a disease complex associated with a variety of bacterial and viral pathogens and environmental and host factors. It is the most common and costly disease of US feedlots (Griffin, 1997; Snowder et al., 2006) and one of the most common diseases of veal operations (Catry et al., 2008). The major bacterial pathogens of BRD include $M$. bovis, M. haemolytica, P. multocida, Histophilus somni, and Arcanobacterium pyogenes (Bryson, 1985; Sivula et al., 1996; Mosier, 1997). The viral pathogens associated with BRD include BHV-1, BVDV, BRSV, and $\mathrm{PI}_{3}$ (Snowder et al., 2006). It is suggested that M. bovis and 
Table 3. Cumulative list of bacteria isolated from environmental air samples at veal farms

\begin{tabular}{|c|c|c|c|c|}
\hline Organism & Herd A & Herd B & Herd C & Herd D \\
\hline Aerococcus viridans & + & + & + & + \\
\hline Bacillus brevis & + & & & + \\
\hline Bacillus megaterium & & & & + \\
\hline Bacillus stearothermophilus & & & & + \\
\hline Bacillus sp. & + & + & + & \\
\hline$C D C$ EF4 RG- & + & & & \\
\hline Enterococcus faecium & + & & & \\
\hline Kocuria varians & + & & & + \\
\hline Lactococcus lactis & + & & & \\
\hline Micrococcus spp. & + & & + & + \\
\hline Pseudomonas aeroginosa & + & & & \\
\hline Pseudomonas putida & + & & & \\
\hline Staphylococcus aureus & & + & & \\
\hline Staphylococcus auricularis & & & & + \\
\hline Staphylococcus capitis & + & + & + & + \\
\hline Staphylococcus caprae & + & & & \\
\hline Staphylococcus carnosus & & & + & + \\
\hline Staphylococcus cohnii & + & + & + & + \\
\hline Staphylococcus epidemidis & + & & & + \\
\hline Staphylococcus haemolyticus & + & & + & + \\
\hline Staphylococcus hominis & & & & + \\
\hline Staphylococcus lentus & + & & + & \\
\hline Staphylococcus saprophiticus & + & & & \\
\hline Staphylococcus sciuri & + & + & & + \\
\hline Staphylococcus xylosus & + & + & + & + \\
\hline
\end{tabular}

P. multocida are secondary pathogens associated with the chronic versions of BRD, leading to poor treatment success (Griffin, 1997). Mycoplasma bovis has been increasingly implicated in veal calf populations of Europe and Canada, with some reported seroconversion rates of 65 to $100 \%$ occurring in feedlots (Ter Laak et al., 1992; Gagea et al., 2006a; Arcangioli et al., 2008; Radaelli et al., 2008). The objectives of this study were to gain an understanding of the role of $M$. bovis and other bacterial respiratory pathogens in the special-fed veal industry of Pennsylvania. Four production units were selected to survey the effect of $M$. bovis.

Mycoplasma bovis was not isolated in environmental air samples collected monthly from the veal raising facilities during this study. One previous report exists of $M$. bovis being successfully cultivated from the air by leaving an agar plate open in the barn (Jasper et al., 1974). Preliminary testing of the sampling media and all-glass impinger collection vessel in a closed biological hood with aerosolized $M$. bovis (ATCC 25523) indicated the ability of the system in our laboratory to culture $M$. bovis successfully from the air. This method should not be used directly to imply the absence of $M$. bovis from the air of the facilities in this study. Sample collection times, transport, the number of colony-forming units of $M$. bovis present in the air, or the presence of other airborne bacteria, viruses, and fungi might have affected our ability to cultivate $M$. bovis in this study. Other bacteria were successfully isolated from the environmental air samples. The largest percentage of bacteria isolated in this study was from the genus Staphylococcus.

The shedding of $M$. bovis by dairy calves with no clinical signs of disease has been reported to range from 0 to $30 \%$ in feedlots (Bennett and Jasper, 1977; Springer et al., 1982; Boothby et al., 1983; Wiggins et al., 2007). The results of this study indicate that when a lung lesion with $M$. bovis is identified, a nasal swab will likely have been positive (94\%). However, a $M$. bovis-positive nasal swab or bronchial swab was not shown to significantly influence the future presence of a lung lesion associated with $M$. bovis infection. This suggests that although colonization of the nasal cavity is likely necessary for the future development of lower respiratory infection, nasal swabs are unable to accurately predict which animals are at highest risk. When it was shown that a single nasal swab was positive (compared with more than one positive swab) before a bronchial swab was found to be positive, the OR was found to be protective $(\mathrm{OR}=0.17)$. This effect might be due to the necessity of chronic nasal colonization leading to bronchial infection, as indicated by multiple positive nasal swabs. This suggests that nasal swabs should only be used as a screening tool for $M$. bovis colonization in a special-fed veal herd rather than an indicator of risk of developing a lung lesion due to $M$. bovis infection because nasal swabs are not significantly associated with lung lesions containing $M$. bovis.

The results of this study suggest that $M$. bovis, in concert with other bacterial respiratory pathogens, is likely 
responsible for pneumonic lesions in veal calves. Of collected lung lesions, it was shown that $41.1 \%$ contained $M$. bovis, indicating that $M$. bovis serves an important role in bacterial respiratory disease of Pennsylvania veal calves. A significant difference between herds B and C (same management in each production unit) was found for the number of lung lesions and percentage of lung lesions containing $M$. bovis, suggesting the possibility of infection differences in some herds based upon time of year. The importance of polymicrobial bacterial infections in the formation of pneumonic lesions in the lung is supported by an OR of 10.8 that a calf with a lung lesion with a member of the Pasteurellaceae family also has $M$. bovis present in the lesion. The lowest incidence and attack rates were seen in calves before $50 \mathrm{~d}$ of age. In agreement with previously published reports, $M$. bovis may therefore be a primary pathogen or initiating factor for polymicrobial bacterial infections (Gourlay and Houghton, 1985). The trends of colonization for $M$. bovis across all animals sampled indicate that vaccines and other prophylactic strategies targeted against $M$. bovis colonization before $50 \mathrm{~d}$ of age would likely reduce the effect of $M$. bovis prevalence.

Mycoplasma bovis infection in the lung was not shown to have a significant effect on the final dress weight for the 4 veal calf herds in Pennsylvania. The mortality rate of calves in the study was low, but because field necropsy was not performed, we could not implicate $M$. bovis as a cause of mortality. Based upon these results, it is difficult to assess the effect of $M$. bovis on herd health in the United States. Despite this, previous studies have reported that $M$. bovis is often found early in the BRD disease process of veal calves (Gourlay and Houghton, 1985; Arcangioli et al., 2008). The results of this study indicate that lung lesions associated with $M$. bovis occurred in $15 \%$ of the calves sampled at the slaughterhouse. This percentage is lower than the anticipated percentage of calf lesions in Europe attributed at least in part to M. bovis (Nicholas and Ayling, 2003). This may be due to the strict nutritional care and moderated temperature and ventilation afforded to veal calves versus calves on stocker, feeder, or heifer raising operations, the younger age of calves sampled in this study, or the number of infected calves purchased. Because European veal calves are reared for longer periods than those in North America, it is possible that milder forms of lung diseases are seen in North America, such as the interstitial pneumonia seen in this study.

In conclusion, $M$. bovis was frequently isolated from URT via nasal swabs, including within $3 \mathrm{~d}$ of arrival in the barn for one herd. The cumulative incidence, attack rates, and the frequency of multiple bacterial respiratory pathogens cultured from nasal swabs, bronchial swabs, and lung lesions suggested that $M$. bovis has the potential to be an initiating factor of respiratory disease in special-fed veal calves from Pennsylvania. Attack rates and cumulative incidence rates may be used in future studies for modeling of $M$. bovis transmission differences in fan ventilation and natural ventilation barns. Further investigation of the effect of M. bovis in special-fed veal from other regions of the United States, as well as vaccine trials targeting young calves, would be beneficial.

\section{ACKNOWLEDGMENTS}

This research was funded by the Pennsylvania Department of Agriculture Bureau of Animal Health and Diagnostic Services Grant ME-447632 (principal investigator: D. R. Wolfgang). The authors thank Wayne Marcho, owner of Marcho Farms Inc. (Harleysville, PA), for his continued support of research and improvements in the US veal industry. We are also grateful to the many veal raisers and processing facility employees of Marcho Farms Inc. and to Roberta Horner (PA Animal Diagnostic Laboratory, University Park) for their indispensable assistance throughout this work.

\section{REFERENCES}

Adegboye, D. S., P. Halbur, D. Cavanaugh, R. Werdin, C. Chase, D. Miskimins, and R. Rosenbusch. 1995. Immunohistochemical and pathological study of Mycoplasma bovis-associated lung abcesses in calves. J. Vet. Diagn. Invest. 7:333-337.

Arcangioli, M. A., A. Duet, G. Meyer, A. Dernberg, P. Bezille, F. Pourmarat, and D. Le Grand. 2008. The role of Mycoplasma bovis in bovine respiratory disease outbreaks in veal calf feedlots. Vet. J. $177: 89-93$.

Bennett, R. H., and D. E. Jasper. 1977. Nasal prevalence of Mycoplasma bovis and IHA titers in young dairy animals. Cornell Vet. 67:361-373.

Boothby, J., D. Jasper, J. Zinkl, C. Thomas, and J. Dillinger. 1983. Prevalence of mycoplasmas and immune responses to Mycoplasma bovis in feedlot calves. Am. J. Vet. Res. 44:831-838.

Bryson, D. G. 1985. Calf pneumonia. Vet. Clin. North Am. Food Anim. Pract. 1:237-257.

Catry, B., L. Duchateau, J. Van De Ven, H. Laevens, G. Opsomer, F. Haesebrouck, and A. De Kruifd. 2008. Efficacy of metaphylactic florfenicol therapy during natural outbreaks of bovine respiratory disease. J. Vet. Pharmacol. Ther. 31:479-487.

Gagea, M. I., K. Bateman, T. Dreumel, B. McEwen, S. Carman, M. Archambault, R. Shanahan, and J. Caswell. 2006a. Diseases and pathogens associated with mortality in Ontario beef feedlots. J. Vet. Diagn. Invest. 18:18-28.

Gagea, M. I., K. Bateman, R. Shanahan, T. Dreumel, B. McEwen, S. Carman, M. Archambault, and J. Caswell. 2006b. Naturally occurring Mycoplasma bovis-associated pneumonia and polyarthritis in feedlot beef cattle. J. Vet. Diagn. Invest. 18:29-40.

Gerchman, I., S. Levisohn, I. Mikula, and I. Lysnyansky. 2009. In vitro antimicrobial susceptibility of Mycoplasma bovis isolated in Israel from local and imported cattle. Vet Microbiol. 137:268-275.

Gourlay, R. N., and S. Houghton. 1985. Experimental pneumonia in conventionally reared and gnotobiotic calves by dual infection with Mycoplasma bovis and Pasteurella haemolytica. Res. Vet. Sci. 38:377-382.

Griffin, D. 1997. Economic impact associated with respiratory disease in beef cattle. Vet. Clin. North Am. Food Anim. Pract. 13:367377. 
Jasper, D. E., J. Al-Aubaidi, and J. Fabricant. 1974. Epidemiological observations on mycoplasma mastitis. Cornell Vet. 64:407-415.

Langford, E. V. 1977. Mycoplasma agalactiae ssp. bovis in pneumonia and arthritis of the bovine. Can. J. Comp. Med. 41:89-94.

Mosier, D. A. 1997. Bacterial pneumonia. Vet. Clin. North Am. Food Anim. Pract. 13:483-493.

Muenster, O. A., E. Ose, and T. Matsuoka. 1979. The incidence of Mycoplasma dispar, ureaplasma, and conventional Mycoplasma in the pneumonic calf lung. Can. J. Comp. Med. 43:392-398.

Nicholas, R. A., R. Ayling, and L. McAuliffe. 2008. Bovine respiratory disease. Pages 132-168 in Mycoplasma Diseases of Ruminates. CAB International, London, UK.

Nicholas, R., R. Ayling, and L. McAuliffe. 2009. Vaccines for mycoplasma diseases in animals and man. J. Comp. Pathol. 140:85-96.

Nicholas, R., S. Baker, R. Ayling, and L. Stipkovits. 2000. Mycoplasma infections in growing cattle. Cattle Pract. 8:115-118.

Nicholas, R. A., and R. D. Ayling. 2003. Mycoplasma bovis: Disease, diagnosis and control. Res. Vet. Sci. 74:105-112.

Pfutzner, H. 1990. Epizootiology of the Mycoplasma bovis infection of cattle. Zentralbl. Bakteriol. Suppl. 20:394-399.

Pfutzner, H., and K. Sachse. 1996. Mycoplasma bovis as an agent of mastitis, pneumonia, arthritis and genital disorders in cattle. Rev. -Off. Int. Epizoot. 15:1477-1494.

Pignatelli, P. 1978. Respiratory disease and the incidence of pulmonary mycoplasmsosis in intensively-reared calves in Italy. Pages 284-294 in Respiratory Diseases in Cattle. W. Martin, ed. Martinus Nijhoff, Boston, MA.

Pospiech, A., and B. Neumann. 1995. A versatile quick-prep of genomic DNA from gram-positive bacteria. Trends Genet. 11:217-218.

Poumarat, F., D. Le Grand, S. Phillippe, D. Calavas, F. Schelcher, P. Cabanie, P. Tessier, and H. Navetat. 2001. Efficacy of spectinomycin against Mycoplasma bovis pneumonia in conventional reared calves. Vet. Microbiol. 80:23-35.
Radaelli, E., M. Luini, G. Loria, R. Nicholas, and E. Scanziani. 2008. Bacteriological, serological, pathological, and immunohistochemical studies of Mycoplasma bovis respiratory infection in veal calves and adult calves at slaughter. Res. Vet. Sci. 85:282-290.

Rosengarten, R., and C. Citti. 1999. The role of ruminant mycoplasmas in systemic infection. Pages 14-17 in Mycoplasmas of Ruminants: Pathogenicity, Diagnostics, Epidemiology and Molecular Genetics. Vol. 3. L. Stipkovits, R. Rosengarten, and J. Frey, ed. European Commission, Brussels, Belgium.

Sivula, N., T. Ames, and W. Marsh. 1996. Descriptive epidemiology of morbidity and mortality in Minnesota dairy heifer calves. Prev. Vet. Med. 27:155-171.

Snowder, G. D., L. Van Vleck, L. Cundiff, and G. Bennett. 2006. Bovine respiratory disease in feedlot cattle: Environmental, genetic, and economic factors. J. Anim. Sci. 84:1999-2008.

Springer, W. T., R. W. Fulton, H. V. Hagstad, S. S. Nicholson, and J. D. Garton. 1982. Prevalence of Mycoplasma and Chlamydia in the nasal flora of dairy calves. Vet. Microbiol. 7:351-357.

Stipkovits, L., P. Ripley, J. Varga, and V. Palfi. 2000. Clinical study of the disease of calves associated with Mycoplasma bovis infection. Acta Vet. Hung. 48:387-395.

Ter Laak, E., A. Wentink, and G. Zimmer. 1992. Increasing prevalence of Mycoplasma bovis in the Netherlands. Vet. Q. 15:100-104.

Thomas, A., I. Dizier, A. Linden, J. Mainil, J. Frey, and E. Vilei. 2004 Conservation of the uvrC gene sequence in Mycoplasma bovis and its use in routine PCR diagnosis. Vet. J. 168:100-102.

Wiggins, M. C., A. Woolums, S. Sanchez, D. Hurley, D. Cole, D. Ensley, and M. Pence. 2007. Prevalence of Mycoplasma bovis in backgrounding and stocker cattle operations. J. Am. Vet. Med. Assoc. 230:1514-1518. 